\title{
Developmental morphometry and allometry of spinal cord
}

\section{S. Maya ${ }^{a}$, A. R. Sreeranjini ${ }^{b}$, C. Leena ${ }^{c}$, N.S. Sunilkumar ${ }^{c}$, K.B. Sumena ${ }^{c}$ and Irshad, $A^{d}$ iD}

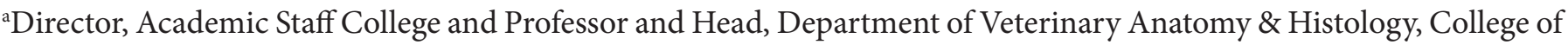
Veterinary and Animal Sciences, Mannuthy, Kerala Veterinary and Animal Sciences University, India

${ }^{\mathrm{b}}$ Associate Professor, Department of Veterinary Anatomy \& Histology, College of Veterinary and Animal Sciences, Mannuthy, Kerala Veterinary and Animal Sciences University, India

'Assistant Professor, Department of Veterinary Anatomy \& Histology, College of Veterinary and Animal Sciences, Mannuthy, Kerala Veterinary and Animal Sciences University, India

${ }^{\mathrm{d} C e n t r e}$ of Excellence in Meat Science and Technology and Department of Livestock Products Technology, College of Veterinary and Animal Sciences, Mannuthy, Thrissur, Kerala, India

Corresponding author: S. Maya | Email: maya@kvasu.ac.in

Co-authors: ARS: sreeranjini@kvasu.ac.in ; CL: leena@kvasu.ac.in ; NSS: sunilkumar@kvasu.ac.in

KBS: sumena@kvasu.ac.in; IA: irshad@kvasu.ac.in

Received: 12-07-2020, Accepted: 13-08-2020, Published online: 21-09-2020

\section{Abstract}

In mammals, the spinal cord forms a long, roughly cylindrical structure with cervical and lumbar enlargements. It is anchored in the vertebral canal, enclosed by meninges. The cord is protected by the epidural fat and terminates as the conus medullaris, which varied in level at different stages of gestation. The weight and length of the cord have significant correlation in between them and with age, body weight, CRL and vertebral column length and other body parameters. All cord segments did not correspond to the corresponding vertebrae. Initially, the spinal cord extended the entire length of vertebral canal. Later it loose its correspondence with vertebral segments as gestation proceeds.

Keywords: Allometry, development, morphometry, spinal cord

\footnotetext{
doi: https://doi.org/10.51128/jfas.2020.A002 / How to cite this article: S. Maya, A. R. Sreeranjini, C. Leena, N.S. Sunilkumar, K.B. Sumena and Irshad, A. 2020. Developmental morphometry and allometry of spinal cord, Journal of Food and Animal Sciences, 01(01): 07-12.

Copyright: Maya, et al. Open Access. This article is distributed under the terms of the Creative Commons Attribution 4.0 International License (http://creativecommons.org/licenses/by/4.0/), which permits unrestricted use, distribution, and reproduction in any medium, provided you give appropriate credit to the original author(s) and the source, provide a link to the Creative Commons license, and indicate if changes were made. The Creative Commons Public Domain Dedication waiver (http://creativecommons.org/publicdomain/zero/1.0/) applies to the data made available in this article, unless otherwise stated.
} 


\section{Introduction}

Spinal cord (medulla spinalis) of adult mammals is the elongated, cylindrical portion of the central nervous system that resides within the vertebral canal, enveloped by the meninges, bathed in the cerebrospinal fluid and anchored in the vertebral canal by ligaments (Kappers et al., 1967). It is not a true cylinder, with a greater transverse width than its dorsoventral diameter and two enlargements at the cervical and lumbar levels, which are related to the innervation of the extremities. Caudally the cord tapers abruptly to become the conus medullaris, which is attached by the filum terminale, a meningeal structure to the fundus of the dural sac at the level of second sacral vertebra in human (Clark, 1984).

Shape of the adult brain and spinal cord is being determined by the spatial and temporal pattern of cell division in the neural tube. The size and internal structure of the spinal cord segments are related to the specializations of the postcranial body. The cervical and lumbar enlargements reflects the accumulation of a greater number of neurons at these levels and the number of neurons within a cord segment varies according to the size and character of the part of the body it served (Ulinski, 1997).

\section{Weight of Spinal Cord}

A direct relationship exists between the spinal cord weight and body weight as observed in cat (Latimer, 1938). In domestic animals, the adult weight of the spinal cord ranges from $270 \mathrm{~g}$ in horse, 240-250 $\mathrm{g}$ in ox, $42 \mathrm{~g}$ in pig, 30-150 $\mathrm{g}$ in dog and 26-29 $\mathrm{g}$ in fowl (Sisson and Grossman, 1953).

The central nervous system is relatively large throughout the foetal period. At birth, the brain contributes 10 per cent of the body weight and in adults it is two per cent in human. The spinal cord overgrows brain during the postnatal years, increasing from 0.9 per cent of the brain weight to two per cent (Arey, 1957). In mice, a linear relationship of growth of spinal cord was demonstrated by Blinderman and Brown (1966), by plotting the growth curves of various divisions of the CNS as percentage of dry weight against bodyweight at different periods of maturation, indicating a uniform growth with respect to each other, of the CNS components except cerebellum.

Richardson and Hebert (1978) also observed a linear relationship between the cube root of organ weight and gestational age in ovine foetuses between 50 and 140 days of age and this linear relationship became sigmoid for the weights of the brain, cerebellum and spinal cord. Further, Taluja et al. (1989) also reported a significant correlation between weight of the spinal cord with that of the foetus in foetal goat, with the values of the former being $0.226 \mathrm{~g}, 0.641 \mathrm{~g}$ and 3.130 $\mathrm{g}$ in first, second and third trimesters of gestation respectively.

On the contrary, in buffalo, the cord weight did not bear any relationship to other body parameters (Sharma and Rao, 1971b).

\section{Total Length of Spinal Cord}

A direct relationship has been reported between the cord length and body length in cat (Kreig and Groat, 1944) and buffalo (Sharma and Rao, 1971b). A highly significant positive correlation has been observed between CRL and length of the spinal cord in all stages of gestation in foetal goat also (Taluja and Shrivastava, 1982).

But in rabbits, the age, weight, sex and method of preparation do not show any correlation with the length of the spinal cord (Greenaway et al., 2001).

The adult length of the spinal cord is reported to be $192.5 \mathrm{~cm}$ in horse, $165-170 \mathrm{~cm}$ in ox, $61 \mathrm{~cm}$ in goat and $38 \mathrm{~cm}$ in dog (Sisson and Grossman, 1953), 310 to $370 \mathrm{~mm}$ in adult cat (Thomas and Combs, 1962), 175 to $280 \mathrm{~mm}$ in Rhesus monkey, 180 to $227 \mathrm{~mm}$ in Irus monkey and 311 to $334 \mathrm{~mm}$ in Baboon (Thomas Combs, 1965). The mean length of the cord is $6.620 \pm 0.093$ $\mathrm{cm}, 11.330 \pm 0.547 \mathrm{~cm}$ and $17.800 \pm 0.602 \mathrm{~cm}$ in first, second and third trimesters of pregnancy respectively, in foetal goat (Taluja and Shrivastava,1982). Whereas, in sheep, the total length of the cord is $177 \pm 18.30$ $\mathrm{mm}$ in third month, $238 \pm 16.15 \mathrm{~mm}$ in fourth month and $326 \pm 23.00 \mathrm{~mm}$ in fifth month of gestation, $470 \pm$ $34.80 \mathrm{~mm}$ in new born lambs and $834 \pm 47.10 \mathrm{~mm}$ in adult sheep (Ghazi and Gholami, 1993).

\section{Regional Length of Spinal Cord}

On the basis of regional distribution of spinal nerves, the spinal cord could be divided into cervical, thoracic, lumbar, sacral and coccygeal regions. In human, the thoracic region is the longest, followed by the cervical, lumbar, sacral and coccygeal regions (Lassek and Rasmussen, 1938).

In domestic animals, the regional cord length is $41 \mathrm{~cm}$ in cervical region, $72 \mathrm{~cm}$ in thoracic region, $32 \mathrm{~cm}$ in lumbar region and $7 \mathrm{~cm}$ in sacral region in ox; $65 \mathrm{~cm}, 86 \mathrm{~cm}, 27 \mathrm{~cm}$ and $15 \mathrm{~cm}$ respectively in horse and $11 \mathrm{~cm}, 17.40 \mathrm{~cm}, 7 \mathrm{~cm}$ and $2.6 \mathrm{~cm}$ respectively in dog, all showing the maximum regional length in the thoracic region (Sisson and Grossman, 1953).

In the Central European hedgehog also, the thoracic region is the longest, with the coccygeal region being longer than the sacral region (Malinska et al., 1972).

In foetal goat also, the maximum regional cord length has been observed in the thoracic region. The regional thoracic cord length, expressed as percentage of the total length of the cord declines from 38.51 per cent in the first trimester to 36.96 per cent in the third trimester. A highly significant positive correlation has also been observed between the total cord length and length of the thoracic region in all age groups (Taluja and Shrivastava, 1982). 
It was similar in sheep, with the thoracic region being the longest in all the age groups followed by the cervical, lumbar, sacral and coccygeal regions (Ghazi and Gholami, 1993).

\section{Allometric Growth with Vertebrae}

Unlike the spinal cord of birds and reptiles, the mammalian spinal cord seldom extends through the entire length of the vertebral canal postnatally. But in early embryonic life, the cord corresponds in length to the vertebral canal and occupies the whole extent of the latter. Due to the unequal growth of the skeleton and the spinal cord later, there occurs a lack of correspondence between the length of vertebral canal and that of the spinal cord; so that in carnivores the conus reaches only upto the end of lumbar column, while in ungulates it extends further even to middle of sacral region (Kappers et al., 1967).

As per the observations in Albino mouse, the cervical region is the most rapidly lengthening region of the cord, followed by the sacral and lumbar regions (Sakla, 1969). In human, the second month of foetal life finds a well-formed spinal cord with spinal nerves attached to it, extending the entire length of vertebral canal. But, later after third month, the vertebral column grows at a faster rate than the spinal cord and by birth,

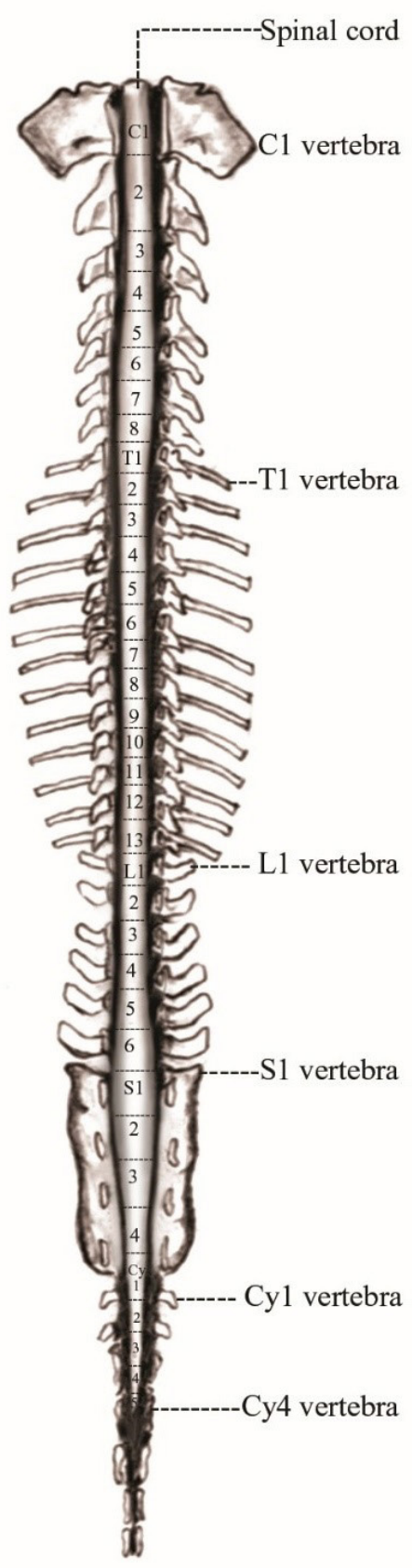

II month

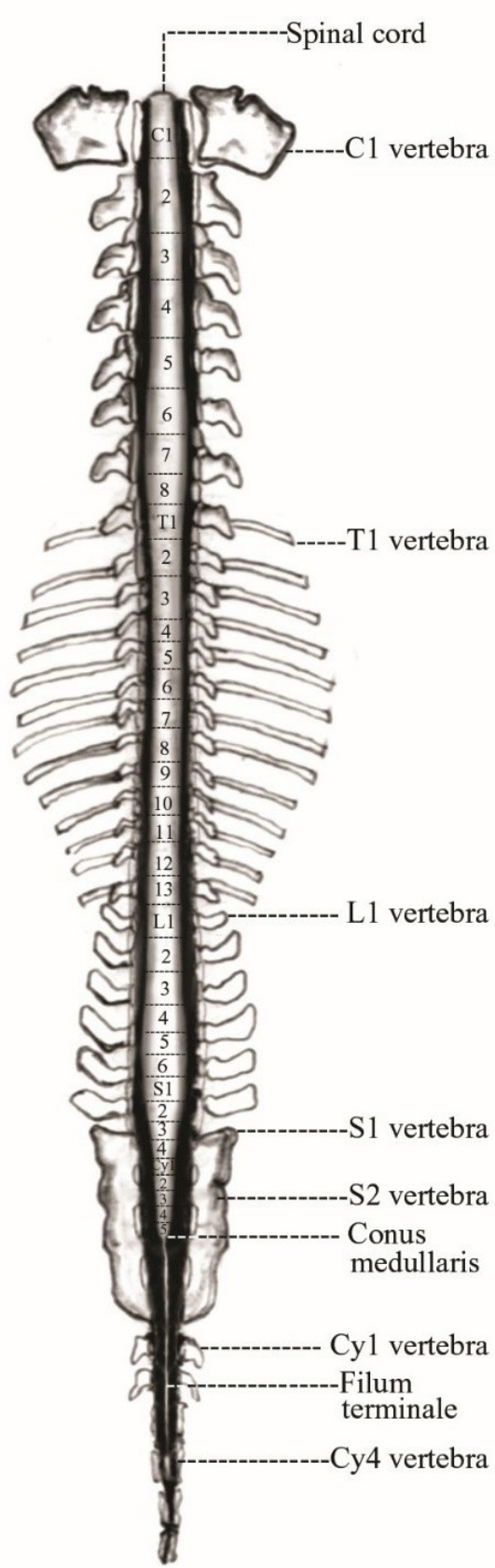

Full term

Figure 1: Correspondence between spinal cord segments and vertebrae in prenatal goat. 
the cord reaches only upto the caudal border of second lumbar vertebra (Harrison, 1978).

Because of this disparity in length between the spinal cord and vertebral column, the nerves from the lumbar and sacral segments travel a long distance before reaching their respective foramina of exit. The cervical and cranial thoracic rootlets will be situated nearly at right angles to the cord, but caudal thoracic, lumbar and sacral rootlets enter and leave the cord at more oblique angles. This discrepancy becomes so pronounced in the caudal third of the vertebral canal that the rootlets run parallel to one another in a cranial to caudal direction, thus forming the cauda equina in mammals (Jenkins, 1978).

In the late teens in human, the spinal cord attains its adult position and terminates at the level of the intervertebral disc between the first and second lumbar vertebrae (Clark, 1984). In sheep (Ghazi and Gholami, 1994) and camel (Ghazi et al.1998a), the vertebral column grows faster than the spinal cord during postnatal life, with variation in growth being observed throughout the length of the cord. In the thoracic region, the growth rate of the spinal cord in relation to the vertebral column was positively allometric; in the cervical region it was isometric and caudal to these regions, there was a decline in growth rate of the spinal cord compared to the respective regions of the vertebral column. Hence, craniocaudally, the growth rate becomes negatively allometric for spinal cord.

\section{Correspondence with Vertebrae}

In domestic animals, four regions are distinguished in terms of segment- vertebra relationship: cranial cervical region, caudal cervical to cranial thoracic region, caudal thoracic to cranial lumbar region and the remainder of the cord. In the first and third regions, the segments lay within the corresponding vertebrae and in second and fourth regions, segments lay cranial to the corresponding vertebrae. The fact that spinal cord was not co extensive with the entire vertebral canal, and the spinal cord segments did not lie within the boundaries of their corresponding vertebrae seems to be a recognizable feature for many species of mammals (Hopkins, 1935).

All the cord segments do not correspond to the transverse and vertical planes of the corresponding vertebrae in cat also (Kreig and Groat, 1944). In domestic animals, the vertebral column overgrew the cord, so that beyond the most cranial cervical region, the cord segments lay cranial to their corresponding vertebrae and the nerve roots made progressively more acute caudal angles to the cord as they proceeded to their appropriate exits (Sisson and Grossman, 1953).

In man, the cranial and middle thoracic vertebrae exhibited an increase in length over the spinal cord segments by the eighth week $(36 \mathrm{~mm})$ of development. Further caudally, the lumbosacral region did not exhibit this differential growth in length until the tenth week. Upto C4 segment, the age related caudal slant of spinal nerves was less marked. But from C5 to T4, this trend was reversed and the spinal nerves exhibited an increasing tail ward slope. Still further, from T5 to T10 spinal nerves showed no change in angulation. Whereas, caudal to T10, spinal nerves lagged behind others in development; and in specimens younger than 11 weeks $(72 \mathrm{~mm})$, the caudal slope lessened as progressed to coccygeal segments. In older specimens, the tail ward slope caudal to T10 segment increased because of the greater rate of elongation of vertebral column over that of the spinal cord with the resultant formation of the cauda equina and filum terminale (Barry, 1956).

Among domestic animals, in ox, all regions of the spinal cord corresponded to the regions of the vertebral column except in the lumbosacral region. The lumbar region of the cord in the species ended at the junction of L5 and L6 vertebrae (Mc Leod, 1958).

In dog, all the cord segments did not correspond to the corresponding vertebrae. The only spinal cord segments found to lie entirely within their numerically corresponding vertebrae were $\mathrm{C} 1$, last two thoracic and the first two or three lumbar segments (Fletcher and Kitchell, 1966).

In buffalo also, all the cord segments did not correspond to the vertebrae. Moreover, of all the spinal cord segments, only C6, last three thoracic and L1 segments were located entirely within their corresponding vertebral limits. Here, the cervical portion of the cord extended from the rostral limit of C1 to the mid-level of C7 vertebra, followed by the thoracic region, which extended upto the junction of T13 and L1 vertebrae with the lumbosacral portion lying between L1 and S1 vertebrae (Sharma and Rao, 1971b). In cat, the cervical segments were distributed within seven cervical vertebrae; and caudally, from L5, the segments were located more cranially than the corresponding vertebrae (Mc Clure et al., 1973). Four regions were distinguished in horses also, in terms of segment-vertebra relationship, similar to the condition seen in other domestic animals (Dellmann and Mc Clure, 1975).

\section{Conclusion}

During a short period of early embryonic life, the spinal cord grows at almost the same rate as the vertebral column thus displaying an isometric growth. This phase is of short duration, since the adjacent vertebral segments increase in length more rapidly than the segments of spinal cord. The differential growth of spinal cord segments and vertebral bodies and the resultant differences in the root emergence pattern at various segments, indicates that the growth is an active process in determining the segment-vertebra relationship. Although vertebral column grow faster than the spinal cord, this was not true in all regions. It is also found that the index of allometric growth was 
not constant in all regions of the spinal cord during prenatal and postnatal lives. The growth of the spinal cord segments in relation to respective vertebrae thus exhibits negative allometry, which continues even into adult life (Ghazi et al., 1998a).

\section{Authorship contribution statement}

S. Maya: Conceptualization, Writing - original draft, Writing - review \& editing, Visualization, Supervision, A. R. Sreeranjini: Conceptualization, Writing review \& editing. C. Leena: Writing - original draft, Writing - review \& editing. N.S. Sunilkumar: Conceptualization, Methodology, Writing - original draft, Writing - review \& editing. K.B. Sumena: Writing - original draft, Writing - review \& editing. Irshad, A: Conceptualization, Writing - original draft, Writing - review \& editing.

\section{Acknowledgments}

All the authors acknowledge and thank their respective Institutes and Universities.

\section{Funding}

This compilation is a review article written by its authors and required no substantial funding to be stated.

\section{Declaration of Competing Interest}

All authors declare that there exist no commercial or financial relationships that could, in any way, lead to a potential conflict of interest.

\section{References}

Arey, L.B. 1957. Developmental Anatomy-A Textbook and Laboratory Manual of Embryology. Sixth edition. W.B. Saunders Company, Philadelphia, p. 676.

Barry, A. 1956. A quantitative study of the prenatal changes in angulation of the spinal nerves. Anat. Rec. 126: 97-110.

Blinderman, E. and Brown, W.J. 1966. Maturation and water composition of murine cerebrum, cerebellum, brain stem and spinal cord. Anat. Rec. 154: 753-758.

Clark, R.G. 1984. Anatomy of the mammalian cord. Hand book of the Spinal Cord (ed. Davidoff, R.A.). Marcel Dekker, New York, pp. 1-77.

Dellmann, H.D. and Mc Clure, R.C. 1975. Central nervous system. Sisson and Grossman's The Anatomy of the Domestic Animals. Fifth edition. (ed. Getty, R.). W.B. Saunders Company,
Philadelphia, pp. 1065-1080.

Fletcher, T.F. and Kitchell, R.L. 1966. Anatomical studies on the spinal cord segments of the dog. Am. J. Vet. Res. 27: 1759-1767.

Ghazi, S.R. and Gholami, S. 1993. A study of the length of the spinal cord in the pre- and postnatal life in Mehraban sheep (Ovis aries). Vet. Res. Commun. 17: 417-420.

Ghazi, S.R. and Gholami, S. 1994. Allometric growth of the spinal cord in relation to the vertebral column during prenatal and postnatal life in the sheep (Ovis aries). J. Anat. 185: 427-431.

Ghazi, S.R., Gholami, S. and Khaksar, Z. 1998 . Allometric growth of the spinal cord in relation to the vertebral column during postnatal life in one humped male camel (Camelus dromedarius). J. Camel Prac. Res. 5: 75-79.

Greenaway, J.B., Partlow, G.D., Gonsholt, N.L. and Fisher, K.R.S. 2001. Anatomy of the lumbosacral spinal cord in rabbits. J. Am. Anim. Hosp. Ass. 37: 27-34.

Harrison, R.G. 1978. Clinical Embryology. Academic Press, London, p. 250.

Hopkins, G.S. 1935. The correlation of anatomy and epidural anaesthesia in domestic animals. Cornell Vet. 25: 263.

Jenkins, T.W. 1978. Functional Mammalian Neuroanatomy. Second edition. Lea and Febiger, Philadelphia, p. 480.

Kappers, C.U.A., Huber, G.C. and Crosby, E.C. 1967. The Comparative Anatomy of the Nervous System of Vertebrates, Including Man. Hafner Publishing Company, New York, p. 695.

Kreig, W.I.E. and Groat, R.A. 1944. Topography of the spinal cord and vertebral column of the cat. $Q$. Bull. Nwest. Univ. Med. 18: 265.

Lassek, A.M. and Rasmussen, G.L. 1938. A quantitative study of the new born and adult spinal cords of man. J. comp. Neurol. 60: 371-379.

Latimer, H.B. 1938. The weights of the brain and of its parts, of the spinal cord and of the eyeballs in the adult cat. J. comp. Neurol. 68: 395.

Malinska, J., Kapoun, S. and Malinsky, J. 1972. Topography of the spinal cord in the east central European hedgehog (Erinaceus roumanicus centroeuropaeus). Folia Morph. 20: 182-184.

Mc Clure, R.C., Dallman, M.J. and Garrett, P.D. 1973. Cat Anatomy: An Atlas, Text and Dissection Guide. Lea and Febiger, Philadelphia, p. 240.

Mc Leod, W.M. 1958. Bovine Anatomy. Second edition. (eds. Trotter, D.M. and Lumb, J.W.). Burgess 
Publishing Company, Minnesota, p. 217.

Richardson, C. and Hebert, C.N. 1978. Growth and pattern of organs and tissues in the ovine foetus. Br. Vet. J. 134: 181-189.

Sakla, F.B. 1969. Quantitative studies on the postnatal growth of the spinal cord and the vertebral column of the albino mouse. J. comp. Neurol. 160: 371-379.

Sharma, D.N. and Rao, G.S. 1971. Topography of spinal cord segments in buffalo (Bubalus bubalis). Indian J. Anim. Sci. 41: 161-165.

Sisson, S. and Grossman, J.D. 1953. The Anatomy of the Domestic Animals. Fourth edition. W.B. Saunders Company, Philadelphia, p. 972.
Taluja, J.S. and Shrivastava, A.M. 1982. Study on regional length of prenatal caprine spinal cord. Indian Vet. J. 59: 700-704.

Taluja, J.S., Shrivastava, A.M. and Malik, M.R. 1989. A metrical study of prenatal caprine spinal cord. Indian J. Anim. Sci. 59: 942-944.

Thomas, C.E. and Combs, C.M. 1962. Spinal cord segments. A. Gross structure in the adult cat. Am. J. Anat. 110: 37-47.

Thomas, C.E. and Combs, C.M. 1965. Spinal cord segments. B. Gross structure in the adult monkey. Am. J. Anat. 116: 205-216.

Ulinski, P.S. 1997. Vertebrate nervous system. Comparative Physiology (ed. Dantzler, W.H.). Oxford University Press, New York, pp. 17-30. 